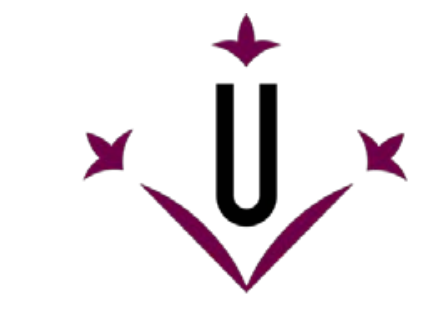

Universitat de Lleida

Document downloaded from:

http://hdl.handle.net/10459.1/63093

The final publication is available at:

https://doi.org/10.1111/pce.12909

Copyright

(C) John Wiley \& Sons Ltd, 2017 


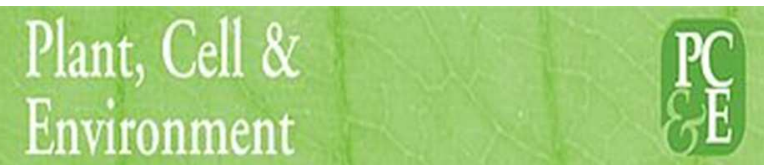

\section{Endogenous circadian rhythms in pigment composition induce changes in photochemical efficiency in plant canopies}

\begin{tabular}{|c|c|}
\hline Journal: & Plant, Cell \& Environment \\
\hline Manuscript ID & PCE-16-0781.R1 \\
\hline Wiley - Manuscript type: & Original Article \\
\hline Date Submitted by the Author: & $\mathrm{n} / \mathrm{a}$ \\
\hline Complete List of Authors: & $\begin{array}{l}\text { Garcia-Plazaola, Jose Ignacio; Universidad del Pais Vasco, Plant Biology } \\
\text { and Ecology } \\
\text { Fernández-Marín, Beatriz; University of the Basque Country (UPV/EHU), } \\
\text { Plant Biology and Ecology } \\
\text { Ferrio, Juan Pedro; Universidad de Concepción } \\
\text { Alday, Josu; University of Lleida, Crop and Forest Sciences } \\
\text { Hoch, Guenter; University of Basel } \\
\text { Landais, Damien; CNRS, Ecotron, UPS } 3248 \\
\text { Milcu, Alexandru; Ecotron Européen de Montpellier } \\
\text { Tissue, David; Western Sydney University, Hawkesbury Institute for the } \\
\text { Environment } \\
\text { Voltas, Jordi; University of Lleida, Crop and Forest Sciences } \\
\text { Gessler, Arthur; Swiss Federal Research Institute WSL, Forest Growth and } \\
\text { Climate } \\
\text { Roy, Jacques; Ecotron Européen de Montpellier } \\
\text { Resco de Dios, Victor; Universitat de Lleida, Department of Crop and Forest } \\
\text { Sciences-AGROTECNIO Center }\end{array}$ \\
\hline Environment Keywords: & circadian \\
\hline Physiology Keywords: & photosynthesis: electron transport, stomata \\
\hline Other Keywords: & pigments \\
\hline Abstract: & $\begin{array}{l}\text { There is increasing evidence that the circadian clock is a significant driver } \\
\text { of photosynthesis that becomes apparent when environmental cues are } \\
\text { experimentally held constant. We studied whether the composition of } \\
\text { photosynthetic pigments is under circadian regulation, and whether } \\
\text { pigment oscillations lead to rhythmic changes in photochemical efficiency. } \\
\text { To address these questions, canopies of bean and cotton were maintained, } \\
\text { after an entrainment phase, under constant (light or darkness) conditions } \\
\text { for } 30-48 \text { h. Photosynthesis and quantum yield peaked at subjective noon } \\
\text { and non-photochemical quenching peaked at night. These oscillations were } \\
\text { not associated to parallel changes in carbohydrate content or xanthophyll } \\
\text { cycle activity. We observed robust oscillations of Chla/b during constant } \\
\text { light in both species, and also under constant darkness in bean, peaking } \\
\text { when it would have been night during the entrainment (subjective nights). }\end{array}$ \\
\hline
\end{tabular}


These oscillations could be attributed to the synthesis and/or degradation of trimeric light-harvesting complex II (reflected by the rhythmic changes in Chla/b), with the antenna size minimal at night and maximal around subjective noon. Considering together the oscillations of pigments and photochemistry, the observed pattern of changes is counterintuitive if we assume that the plant strategy is to avoid photo-damage, but consistent with a strategy where non-stressed plants maximize photosynthesis.

SCHOLARONE
Manuscripts 
1 Endogenous circadian rhythms in pigment composition induce changes in 2 photochemical efficiency in plant canopies

3 Running title: Circadian rhythms and pigments

4 José Ignacio García-Plazaola ${ }^{1}$, Beatriz Fernández-Marín ${ }^{1,2}$ Juan Pedro Ferrio $^{3,4}$, Josu G.

5 Alday $^{3}$, Günter Hoch $^{5}$, Damien Landais ${ }^{6}$, Alexandru Milcu ${ }^{6,7}$, David T Tissue ${ }^{8}$, Jordi

6 Voltas $^{3}$, Arthur Gessler ${ }^{9,10}$, Jacques Roy ${ }^{6}$, Víctor Resco de Dios ${ }^{3,8}$

7 Institutions: ${ }^{1}$ Department of Plant Biology and Ecology, University of the Basque 8 Country (UPV/EHU), Bilbao, Spain; ${ }^{2}$ Institute of Botany, University of Innsbruck,

9 Innsbruck, Austria; ${ }^{3}$ Department of Crop and Forest Sciences-AGROTECNIO Center, 10 Universitat de Lleida, Lleida, Spain; ${ }^{4}$ Departamento de Botánica, Facultad de Ciencias 11 Naturales y Oceanográficas, Universidad de Concepción, Casilla 160-C, Concepción, 12 Chile; ${ }^{5}$ Department of Environmental Sciences - Botany, University of Basel, 13 Schönbeinstrasse 6, 4056 Basel, Switzerland; ${ }^{6}$ Ecotron Européen de Montpellier, 14 CNRS, UPS-3248, Montferrier-sur-Lez, France; ${ }^{7}$ Centre d'Ecologie Fonctionnelle et 15 Evolutive, CEFE-CNRS, UMR-5175, Université de Montpellier - Université Paul 16 Valéry - EPHE, 1919 route de Mende, F-34293, Montpellier Cedex 5, France; $17{ }^{8}$ Hawkesbury Institute for the Environment, Western Sydney University, Richmond, 18 NSW, Australia; ${ }^{9}$ Swiss Federal Institute for Forest, Snow and Landscape Research, Birmensdorf, Switzerland; ${ }^{10}$ Institute for Landscape Biogeochemistry, Leibniz-Centre for Agricultural Landscape Research (ZALF), Müncheberg, Germany.

\section{Corresponding author:}

22 José Ignacio García Plazaola, Department of Plant Biology and Ecology, University of 23 the Basque Country (UPV/EHU), Barrio Sarriena s/n, 48940 Bilbao, Spain 


\section{ABSTRACT}

There is increasing evidence that the circadian clock is a significant driver of photosynthesis that becomes apparent when environmental cues are experimentally held constant. We studied whether the composition of photosynthetic pigments is under circadian regulation, and whether pigment oscillations lead to rhythmic changes in photochemical efficiency. To address these questions, canopies of bean and cotton were maintained, after an entrainment phase, under constant (light or darkness) conditions for 30-48h. Photosynthesis and quantum yield peaked at subjective noon and nonphotochemical quenching peaked at night. These oscillations were not associated to parallel changes in carbohydrate content or xanthophyll cycle activity. We observed robust oscillations of Chla/b during constant light in both species, and also under constant darkness in bean, with peakspeaking when it would have been night during the entrainment (during subjective nights). These oscillations could be attributed to the synthesis and/or degradation of trimeric light-harvesting complex II (reflected by the rhythmic changes in Chla/b), with the antenna size minimal at night and maximal around subjective noon. Considering together the oscillations of pigments and photochemistry, the observed pattern of changes is counterintuitive if we assume that the plant strategy is to avoid photo-damage, but consistent with a strategy where nonstressed plants maximize photosynthesis. 


\section{INTRODUCTION}

Because of Earth's rotation, light and temperature oscillate over the course of a day in a very predictable manner. As a consequence of such rhythmic oscillations, optimal and unfavourable time intervals for physiological activities can be anticipated. To be able to take advantage of these predictable oscillations, living organisms have developed a mechanism, the circadian clock, which coordinates physiological processes with environmental conditions. Circadian clocks are ubiquitous in nature and present in almost all groups of organisms examined to date (cyanobacteria, fungi, algae, plants, insects or vertebrates) (Bell-Pedersen et al. 2005).

In plants, the circadian clock originates from a feedback system of coordinated gene expression. In a process known as entrainment (McClung 2006; 2013), external cues such as photoperiod set the circadian clock aiming to synchronize plant performance with environmental fluctuations (Hotta et al. 2007). These circadian oscillations are masked by the alternating light/dark cycles, being usually revealed when plants are deprived of external cues and maintained under constant environmental conditions for protracted periods of time $(>24 \mathrm{~h})$. Therefore, circadian regulation is more apparent, but not more important in constant conditions. Components of the clock include transcription factors that regulate the expression of other genes involved in the clock output, particularly those that regulate physiological processes and developmental events (Hanano et al. 2008). As a result of such coordinated regulation of gene expression, it has been estimated that at least one-third of the Arabidopsis transcriptome shows circadian resonance (Covington et al. 2008), including as much as $70 \%$ of chloroplast-encoded genes (Noordally et al. 2013). Through the control of gene expression, circadian clocks regulate the abundance and activity of proteins involved in physiological processes and, consequently, of metabolite pools. However, the mechanistic linkage between transcription and the final physiological output is still not well understood.

Photosynthetic responses are typically clock-controlled and, under constant environmental conditions, circadian rhythms are among the main drivers of photosynthesis (Dodd et al. 2014). These regulatory effects on photosynthesis are achieved through the hierarchical oscillation of the clock on each type of cell (Endo 2016) modulating the structure and dynamics of the photosynthetic apparatus (Dodd et al. 2014; Harmer et al. 2000). Furthermore, some evidence also points to an important 
regulatory role under oscillating "natural" conditions, at plant and even at ecosystem levels (Doughty et al. 2006; Resco de Dios et al. 2012, Resco de Dios et al. 2016b). In fact, the expression of genes involved in biosynthesis of carotenoids (Covington et al. 2008; Pan et al. 2009), chlorophylls (Harmer 2009; Khan et al. 2010) and pigment binding proteins (Schmid 2008) have been documented to oscillate synchronically during day/night cycles. Carbohydrate levels also affect the expression of circadianregulated genes, controlling and being controlled by photosynthetic rate (Haydon et al. 2013).

The internal maintenance of rhythms in photosynthesis provides an adaptive advantage, such as the capacity to anticipate predictable environmental change (Yerushalmi \& Green 2009; Hotta et al. 2007; Salmela et al. 2016). Diurnal rhythmicity in photosynthesis could potentially lead to two contrasting strategies: i) a conservative strategy of maximizing photoprotection at peak light intensities, at the expense of potentially losing efficiency or, ii) a more risky strategy of maximizing light harvesting, at the expense of potentially suffering photo-damage. It has been shown that Arabidopsis plants with internal clocks in resonance with day-night cycles are able to fix more carbon, grow faster and survive better than mutants with impaired rhythmicity (Dodd et al. 2005). Studies with non-model species are scarcer in the literature, but most support an adaptive role for the circadian rhythms of photosynthesis; e.g. assimilation rates and biomass accumulation correlate positively with the length of circadian periods in Brassica rapa (Yarkhunova et al. 2016), above-ground biomass is higher with clock periods close to $24 \mathrm{~h}$ in Boechera stricta (Salmela et al. 2016), and genotypic variation in the capacity to anticipate sunrise correlates with photosynthesis and growth in Eucalyptus camaldulensis (Resco de Dios et al. 2016a).

Overall, from molecular to organelle scale, the control over photosynthetic processes by circadian clocks is well documented. There are also hints from indirect approaches (statistical filtering, e.g. Resco de Dios et al. 2012; 2016b) that the circadian control of photosynthesis scales up to ecosystem-level fluxes. However, the assessment of the processes driving circadian regulation of photosynthesis has been typically performed at molecular scales by studying rhythmic regulation in the transcriptome and metabolome (Dodd et al. 2014). This contrasts with the "classical" approach in ecophysiology, where $\mathrm{C}$ assimilation is considered to be determined either by diffusional (resistance to $\mathrm{CO}_{2}$ diffusion from the stomata to the site of carboxylation) or biochemical limitations 
113 (Farquhar \& Sharkey 1982; Flexas et al. 2012). While the literature is rich in molecular

114 assessments of circadian regulation of photosynthesis, integrative studies on circadian

115 control of photosynthesis at ecophysiological scales are, to the best of our knowledge,

116 non-existent ( $c f$ review by Dodd et al. 2014).

117 Furthermore, whether the contribution of these rhythms to plant fitness differs across

118 different species has been rarely tested. For instance, if contrasting patterns of daily

119 rhythms in photochemical activity exist among different life forms, that could indicate

120 the existence of trade-offs that modify the physiological output so as to adapt the

121 photosynthetic performance to different life strategies. Therefore, in the present work

122 we aim at, first, characterising the photosynthetic output of circadian rhythms at scales

123 relevant for ecophysiology, that is whether photosynthesis is regulated by diffusional or

124 biochemical constraints; second, whether such photosynthetic output differs among

125 species with different life-history strategies; and third, whether the photosynthetic

126 output also involves circadian changes in photosynthetic pigment composition. To

127 accomplish our goals and with the aim to understand the clock function beyond the

128 Arabidopsis model, we have characterised photosynthetic responses under constant

Formatted: Font: Italic environmental conditions in two species of high agronomic value belonging to

130 contrasting life forms: bean (Phaseolus vulgaris), an annual herb, and cotton 131 (Gossypium hirsutum), a perennial shrub. 


\section{METHODS}

\section{Experimental design}

The experiment was performed at the Macrocosms platform of the Montpellier European Ecotron, Centre National de la Recherche Scientifique (CNRS, France, www.ecotron.cnrs.fr). We used 6 controlled environment units/macrocosms ( 3 planted with bean and 3 with cotton) where the main abiotic drivers (air temperature, humidity and $\mathrm{CO}_{2}$ concentration) were automatically controlled. In each macrocosm, plants were grown on a soil (area of $2 \mathrm{~m}^{2}$, depth of $2 \mathrm{~m}$ ) contained in a lysimeter resting on a weighing platform. The intact soil monoliths were extracted from the flood plain of the Saale River near Jena, Germany, and used in a previous Ecotron experiment on biodiversity (Milcu et al. 2014). After that experiment, the soil was ploughed down to $40 \mathrm{~cm}$ and fertilized with 25/25/35 NPK ( $\mathrm{MgO}, \mathrm{SO}_{3}$ and other oligoelements were associated in this fertilizer: Engrais bleu universel, BINOR, Fleury-les-Aubrais, FR).

Bean and cotton were planted in 5 rows within each macrocosm on $10^{\text {th }}$ July 2013, one month before the start of the measurements, and thinned to densities of 9 to 11 individuals $\mathrm{m}^{-2}$. Cotton (STAM-A16 variety by INRAB/CIRAD) is a perennial shrub with an indeterminate growth habit. STAM-A16 grows to $1.5-2 \mathrm{~m}$ tall and has a pyramidal shape and short branches. Bean (recombinant inbred line RIL-115 bred by INRA Eco\&Sol) is an annual herbaceous species. RIL-115 is a fast growing, indeterminate dwarf variety, 0.3-0.5 m tall; it was inoculated with Rhizobium tropici CIAT 899 also provided by INRA. During the experiment, bean and cotton generally remained at the inflorescence emergence developmental growth stage (Munger et al. 1998; codes 51-59 in BBCH scale, the standard phenological scale within the crop industry; Feller et al. 1995).

Environmental conditions within the macrocosms (excluding the experimental periods) were set to mimic outdoor conditions, but did include a $10 \%$ light reduction by the macrocosm dome cover (sheet of Fluorinated Ethylene Propylene). The soil was regularly watered to field capacity by drip irrigation, although irrigation was stopped during each measurement campaign (few days) to avoid interference with water flux measurements. However, no significant differences (at $P<0.05$, paired t-test, $\mathrm{n}=3$ ) in leaf water potential occurred between the beginning and end of these measurement 
campaigns, indicating no effect of a potentially declining soil moisture on leaf hydration (Resco de Dios et al. 2015).

During experimental periods, the natural light was blocked by placing a completely opaque fitted cover (PVC coated polyester sheet Ferrari 502, assembled by IASO, Lleida, Spain) on each dome, which allowed full control of the light regime using a set of 5 dimmable plasma lamps (GAN 300 LEP with the Luxim STA 41.02 bulb, delivering a sun-like light spectrum, Fig. S1) (Resco de Dios et al. 2016b). The lamps were hung $30 \mathrm{~cm}$ above the plant canopy and provided a PAR of $500 \mu \mathrm{mol} \mathrm{m}^{-2} \mathrm{~s}^{-1}$ at the top of the canopy, when not dimmed. We measured PAR at canopy level with a quantum sensor (Li-190, LI-COR Biosciences, Lincoln, NE, USA) in each macrocosm. The plants adapted to the new conditions during a entrainment period of five days, in which photoperiod was set to $12 \mathrm{~h}$ of darkness and $12 \mathrm{~h}$ of light, with gradual changes in light intensity. After the entrainment period, in the night-time experiments we maintained PAR, air temperature $\left(\mathrm{T}_{\text {air }}\right)$ and vapour pressure deficit (VPD) constant at midnight values for 30 hours starting at solar midnight. In the daytime experiments, we maintained PAR, $T_{\text {air }}$ and VPD constant at noon values for 48 hours starting at solar noon.

\section{Leaf gas exchange and chlorophyll florescence}

We measured leaf net assimilation rate $\left(A_{\text {net }}\right)$, stomatal conductance $\left(\mathrm{g}_{\mathrm{s}}\right)$, maximum assimilation rate $\left(A_{\max }\right)$ and chlorophyll fluorescence using portable photosynthesis systems (LI-6400-40XT, Li-Cor, Lincoln, Nebraska, USA), after setting the leaf cuvette to the same environmental conditions as in the macrocosms, except for $A_{\max }$ which was measured at saturating PAR $\left(2,000 \mu \mathrm{mol} \mathrm{m}^{-2} \mathrm{~s}^{-1}\right)$ and $\mathrm{CO}_{2}(2,000 \mathrm{ppm})$. We conducted measurements every $4 \mathrm{~h}$ in three leaves situated in the upper light-exposed part of the canopy within each macrocosm, and average values for each of the 3 macrocosms per species were used in subsequent analyses. Different leaves from different individuals were measured during each measurement round. Leaf temperature was independently measured at the time of gas exchange measurements with an infra-red thermometer (MS LT, Optris GmbH, Berlin, Germany) and no significant difference with air temperature recorded by the $T_{\text {air }}$ probe (PC33, Mitchell Instrument SAS, Lyon, France) was observed (intercept $=-4.3 \pm 4.5[$ mean $\pm 95 \% \mathrm{CI}]$; slope $=1.15 \pm 0.17 ; \mathrm{R}^{2}=0.89$ ). Chlorophyll fluorescence measurements were made immediately after gas exchange 
measurements. During daytime, steady-state fluorescence (Fs) was measured, followed by a saturating pulse of $c a .8000 \mu \mathrm{mol} \mathrm{m}^{-2} \mathrm{~s}^{-1}$ to determine maximum fluorescence in the light $\left(\mathrm{Fm}^{\prime}\right)$. Derived values of effective quantum yield $\left(\Phi_{\mathrm{PSII}}\right)$ were estimated as (Fm'-Fs)/Fm' (Genty et al. 1989). During nightime, dark-acclimated minimal fluorescence (Fo) was measured, followed by a saturating flash to determine the maximum fluorescence in the dark (Fm). Fm determination allowed the calculation of non-photochemical quenching (NPQ) as (Fm-Fm')/Fm'.

\section{Pigment determination}

Following each set of gas exchange measurements, we collected leaves from two plants (one per individual) per measuring round in each macrocosm, which were immediately frozen in liquid nitrogen and stored at $-80^{\circ} \mathrm{C}$ until biochemical analysis. Frozen samples were homogenised with a mortar in pure acetone solution buffered with $\mathrm{CaCO}_{3}$. The extracts were centrifuged at $16100 \mathrm{~g}$ for $20 \mathrm{~min}$, and supernatants were filtered with 0.2 $\mu \mathrm{m}$ PTFE filters (Teknokroma, Spain). Chlorophylls (Chl) and carotenoids (Car) separation were performed by HPLC with a reverse phase C18 column (Spherisorb ODS1, $4.6 \times 250 \mathrm{~mm}$, Waters, Milford, MA, USA) with a photodiode array (PDA) detector, following the method by García-Plazaola \& Becerril $(1999,2001)$. The total VAZ pool was calculated as the sum of violaxanthin, antheraxantin and zeaxantin. The de-epoxidation index (AZ/VAZ) was calculated as the sum of antheraxantin and zeaxantin) divided by VAZ.

\section{Non-structural carbohydrates}

The same leaf samples that were used for pigment analyses were also used for the determination of non-structural carbohydrates (NSC), defined here as the sum of starch and the three most abundant low molecular weight sugars: sucrose, glucose and fructose. NSC were analysed photometrically after enzymatic conversions of the target carbohydrates following a modified version of the protocol described in Hoch et al. (2002). The dried leaves were ground to fine powder on a ball mill (MM 400, Retsch, Germany) and stored well-sealed over silica gel until analyses. Approximately $10 \mathrm{mg}$ of plant powder was extracted with $2 \mathrm{ml}$ distilled water in glass vials over steam for 30 min. An aliquot of the extract was used for the determination of low molecular 
carbohydrates after enzymatic conversion of fructose and sucrose to glucose (using phosphoglucose isomerase and invertase form bakers yeast). The concentration of total free glucose was then determined on a 96-well multiplate photometer (Multiscan EX, Thermo Scientific, Waltham, MA, USA) after enzymatic conversion of glucose to gluconat-6-phosphate using a glucose hexokinase (GHK) assay reagent (G3292). Following the degradation of starch to glucose with amyloglucosidase from Aspergillus niger at $49^{\circ} \mathrm{C}$ overnight, NSC was determined in a separate analysis. All enzymes were purchased from Sigma-Aldrich (St. Louis, MO, USA). The concentration of starch was calculated as NSC minus the free low molecular carbohydrates. Tissue concentrations were given on $\%$ dry matter basis.

\section{Statistical analyses}

241 We examined temporal patterns of 14 variables: $\left(A_{\text {net }}, g_{\mathrm{s}}, A_{\text {net }} / C_{\mathrm{i}}, A_{\max }, \mathrm{Fm}, \mathrm{Fm}\right.$ ', ФPSII, 242 NPQ, Chla/b, Car/Chl, VAZ/Chl, AZ/VAZ, NSC, starch) with Generalized Additive 243 Model (GAM) fitted with automated smoothness selection (10-15 nodes, Wood, 2006) 244 in the R software environment ( $m g c v$ library in R 3.1.2, The R Foundation for Statistical 245 Computing, Vienna, Austria). We used best-fit line from model predictions to estimate 246 the extent of the diurnal oscillation (maximum minus minimum) during entrainment and 247 during free-running (constant condition) phases. 
RESULTS

250 Circadian oscillations of net assimilation rate $\left(A_{\text {net }}\right)$ were observed when plants were shifted to continuous light conditions after the 5-day entrainment period (Fig. 1a). During entrainment, $A_{\text {net }}$ in $P$. vulgaris ranged from $-3.6 \mu \mathrm{mol} \mathrm{m}^{-2} \mathrm{~s}^{-1}$ during the night up to a maximum of $19.9 \mu \mathrm{mol} \mathrm{m} \mathrm{m}^{-2} \mathrm{~s}^{-1}$ at noon (as estimated from the GAM best fit line). During the constant conditions phase, $A_{\text {net }}$ oscillated from 7.7 to $15.8 \mu \mathrm{mol} \mathrm{m}^{-2} \mathrm{~s}^{-1}$. Therefore the oscillation observed during constant conditions $\left(15.8-7.7=8.1 \mu \mathrm{mol} \mathrm{m} \mathrm{m}^{-2} \mathrm{~s}^{-}\right.$ ${ }^{1}$ ) was $34 \%$ of that observed during entrainment (period -24 to $0 \mathrm{~h}$ in Figure 1) (8.1/24.3 $\times 100)$. Similarly, for cotton we observed that the oscillation in $A_{\text {net }}$ was $37 \%$ of that recorded during entrainment. Circadian oscillations of stomatal conductance $\left(g_{\mathrm{s}}\right)$ were also observed, representing $72 \%$ and $63 \%$ of those in the entrainment phase in bean and cotton, respectively (Fig. 1b). Under constant light conditions, both parameters ( $A_{\text {net }}$ and $g_{\mathrm{s}}$ ) peaked around subjective noon and declined during subjective nights (when species, the frequency of the oscillation was similar and close to $24 \mathrm{~h}$, but the relative magnitude of the oscillation in $A_{\text {net }}$ was 2- to 4-fold smaller than in $g_{s}$. Oscillations in

266 (18\%), but maintained closer to the entrainment phase in cotton (69\%) and attenuated in both species after the first $24 \mathrm{~h}$ in constant conditions. Contrasting with these parameters, maximum assimilation rate $\left(A_{\max }\right)$ did not show any consistent rhythmic oscillation (Fig. 1d). the first $24 \mathrm{~h}$ of continuous light in both species (Fig. 2a). The rhythm showed a tendency to weaken during the second $24 \mathrm{~h}$ cycle. In the case of bean, this oscillation was particularly remarkable, attaining an amplitude of 0.064 , which was half of that measured in the entrainment phase $(0.140)$. In both species, non-photochemical quenching (NPQ) can also be described by an oscillatory behaviour (Fig. 2b2c). The amplitude of the oscillation was maintained during the whole illumination period in bean, but it dampened towards the end of the 48-h period of constant illumination in cotton. Oscillations in NPQ were oppositely phased with those in $\Phi_{\mathrm{PSII}}$, peaking during subjective nights. As measurements of NPQ require illumination, it was not possible to compare the 24-h amplitude of this rhythm with that during the entrainment phase (which contains dark periods). 
Oscillations in $\Phi_{\mathrm{PSII}}$ and NPQ in plants maintained under continuous illumination were due to rhythmic changes in the maximal fluorescence of illuminated leaves (Fm'), which peaked during subjective days (Fig. $3 a \underline{2 b}$ ). During the first $24 \mathrm{~h}$ the amplitude of these oscillations was 3 -fold higher in bean compared to cotton. Interestingly, the maximal fluorescence of dark-adapted leaves (Fm) also oscillated in bean, but not in cotton, when plants were maintained in continuous darkness and constant environmental conditions (Fig. 3b2d).

In bean plants entrained to day/night cycles, there was a robust oscillation of the chlorophyll $a$ to chlorophyll $b$ ratio $(\mathrm{Chl} a / b)$ that was maintained when plants were transferred to continuous light (Fig. 4a $\underline{3 a}$ ). Under constant conditions this ratio peaked during subjective nights, with the amplitude of the oscillation being even higher than during the entrainment phase ( $115 \%$ and $182 \%$ higher in bean and cotton, respectively). Furthermore, under continuous darkness (Fig. $4 \mathrm{~b} \underline{\mathrm{b}}$ ), the same oscillation of $\mathrm{Chl} a / b$ was maintained, with identical magnitude ( 0.41 vs 0.46 in continuous light or darkness, respectively) and peak time. In cotton, the oscillation was attenuated compared to bean, and disappeared during the second $24 \mathrm{~h}$ cycle. The total pool of xanthophyll cycle pigments expressed on a chlorophyll basis (VAZ/Chl) oscillated rhythmically, but was differently phased in bean and cotton (Fig. 5aaa). In bean, VAZ/Chl peaked around subjective noon, while in cotton it peaked around subjective dusk, and the oseillation period was progressively shortened. The same oscillatory trends were observed in the carotenoid to chlorophyll ratio (Car/Chl) (Fig. 5c $\underline{54 \mathrm{~b}}$ ). In contrast, the de-epoxidation index (AZ/VAZ) varied greatly among plants and sampling times, but did not show any consistent oscillatory pattern (Fig $5 b \underline{54 c)}$ ); however, an increasing trend during continuous illumination was observed.

During the entrainment phase, total non-structural carbohydrates (NSC) accumulated during the day and were consumed during the night in both species (Fig. 65 ). However, when transferred to continuous light, they followed a distinct pattern in bean and cotton. In bean, NSC and starch accumulated very fast during the first subjective day, and after the start of the first subjective night the accumulation rate slowed, but continued at a constant rate until the end of the experiment. In the case of cotton it described a rhythmic oscillation, accumulating during the subjective day, with a peak around dusk, and a subsequent decrease during the course of the subjective night. 
As a consequence of the parallel oscillation under constant light of $A_{\text {net }}$ and $g_{\mathrm{s}}$, a tight correlation between them, with different slope for bean and cotton, was observed (Fig. $7 a 6 a)$. However, when both species were considered together (red+blue dots in Figure $7 \mathrm{a} \underline{6 \mathrm{a}}$ ), the linearity of the relationship disappeared at $g_{\mathrm{s}}$ values higher than $0.2 \mathrm{~mol} \mathrm{~m}^{-2} \mathrm{~s}^{-}$ 1. These observations may indicate that $g_{\mathrm{s}}$ was the leading process controlling $A_{\text {net }}$ oscillations by changing $C_{\mathrm{i}}$ (Fig. $7 \mathrm{~b} \underline{6 \mathrm{~b}}$ ). However, contrasting with $g_{\mathrm{s}}$, the correlation between $C_{\mathrm{i}}$ and $A_{\text {net }}$ was only significant in bean. The observed oscillations in $A_{\text {net }}$ also correlated linearly with changes in $\Phi_{\mathrm{PSII}}$ in both species (Fig. $7 \mathrm{e} \underline{6 \mathrm{c}}$ ). Finally, $A_{\text {net }}$ oscillations were negatively related to changes in $\mathrm{Chl} a / b$ in bean (Fig. $7 \mathrm{~d} \underline{6 \mathrm{~d}}$ ).

\section{DISCUSSION}

Carbon assimilation and stomatal opening are known to be clock-controlled processes in plants (Pallas et al. 1974; Hennessey et al. 1993). Accordingly, we observed parallel oscillations of $A_{\text {net }}$ and $g_{\mathrm{s}}$ in bean and cotton (Fig. 1). Initially, it would appear that stomatal conductance is the process that leads the oscillation through the regulation of the availability of $\mathrm{CO}_{2}$ for carboxylation. However, as described in Arabidopsis and other plants (Dodd et al. 2004; Wyka et al. 2005), both processes were not functionally related since $A_{\text {net }}$ was not related to $C_{\mathrm{i}}($ Fig. $6 \underline{6 \mathrm{76b}}$ ), at least in beancotton. The effect of $g_{\mathrm{s}}$ on $A_{\text {net }}$ is generally indirect through regulation of $\mathrm{CO}_{2}$ supply. Hence, if $C_{\mathrm{i}}$ and $A_{\text {net }}$ are not correlated, we can discard $g_{\mathrm{s}}$ as a significant driver of $A_{\text {net }}$ variation under continuous light. Alternatively, circadian rhythms in $A_{\text {net }}$ could also be driven by oscillations in mesophyll conductance, Rubisco activity, light harvesting efficiency, feedback interactions of assimilates with photosynthesis or electron transport. The first two explanations seem unlikely considering that neither $A_{\text {net }} / C_{\mathrm{i}}$ nor $A_{\max }$ showed a rhythmic pattern sustained more than $24 \mathrm{~h}$ (Fig. 1).

Recently, rhythmic changes in photochemical quenching have been characterised in Arabidopsis and identified as controlled by a phototropin related mechanism (Litthauer et al. 2015). In the present study, fluorescence parameters indicative of photochemical use of energy ( $\underline{\Phi S I I}_{\mathrm{PS}} \mathrm{F} / \mathrm{Fm}$ ' and NPQ) also oscillated rhythmically in bean and cotton (Fig. 2). However, both parameters showed an opposite behaviour: $\underline{\Phi}_{\mathrm{PSII}} \mathrm{AF} / \mathrm{Fm}$, which describes the yield of photon capture, peaked during subjective days, while NPQ, which is a proxy of the rate of energy dissipation, peaked during subjective nights. The 
opposite behaviour of both parameters is expected, as both parameters are affected by Fm' but in opposite directions. However, oscillations in Fm' (Fig. 3a2b) may be generated by processes other than photochemistry, such as antenna size adjustments or chloroplast movements (Cazzaniga et al. 2013). Surprisingly, under continuous darkness, Fm also oscillated, at least in bean, and this oscillation cannot be explained by any light-triggered phenomenon, such as chloroplast relocation. Thus, changes in antenna size and/or photochemical efficiency are likely the factors involved in such oscillation.

Functionally, these trends imply that plants maximize efficiency during the day and dissipation at night. A study of delayed fluorescence revealed that nucleus-controlled rhythms in PSII photochemistry are present in most plant species (Gould et al. 2009). However, this rhythmic pattern is not universal; e.g. oscillations in photochemistry follow an opposite pattern in the CAM plant Kalanchoe daigremontiana, peaking at night, as a CAM plant is expected to follow the opposite patter to $\mathrm{C} 3 / \mathrm{C} 4$ photosynthesis (Wyka et al. 2005). These different rhythms indicate coordination between the physiological output of the clock and the requirements of different photosynthetic pathways and life strategies, but in-depth knowledge regarding this oscillation remains limited.

The amplitude of NPQ is regulated by three factors (García-Plazaola et al. 2012): the generation of a proton gradient across the thylakoid membrane, the presence of the protein PsbS, and the formation of zeaxanthin $(Z)$ through the xanthophyll cycle. Among them, a differential xanthophyll cycle activity could justify these oscillations, mainly considering that the expression of the two enzymes that participate in the cycle, VDE (violaxanthin de-epoxidase) (Zhao et al. 2012; Covington et al. 2008) and ZE (zeaxanthin epoxidase) (Audran et al. 1998), is also clock-controlled. However, we did not find any evidence pointing to a circadian regulation of xanthophyll cycle activity (Fig. $5 \underline{\mathrm{c} 4 \mathrm{c}}$ ). Similarly, in an experiment with coral endosymbiotic algae, Sorek et al. (2013) failed to detect circadian rhythm in the diadinoxanthin cycle, while Fv/Fm maintained the oscillation, suggesting the involvement of factors independent of xanthophyll cycle activity. Alternatively, changes in NPQ could be the consequence, rather than the cause, of the oscillating pattern of carbon assimilation. Decreased energy usage for photosynthesis during subjective nights implies greater proton gradient and, 
consequently, higher NPQ. If this is the case, then another factor must trigger the oscillations in assimilation rate.

A straightforward explanation might be that the clock is under feedback control by the products of photosynthesis (sucrose and starch), controlling and being controlled by carbon assimilation (Müller et al. 2014). This could be the case in cotton, in that the starch content oscillated (Fig 65), peaking at subjective dusk and later metabolized during subjective night. Equally, in Arabidopsis starch and sugar are metabolized at night in a process that is under circadian control (Graf et al. 2010). As observed in cotton, metabolization proceeds almost linearly, ensuring that starch availability is maintained until the following dawn (Gibon et al. 2004). In bean, there was also a complete consumption of starch during the night, but contrasting with cotton, the rhythm was not observed in the free-running phase under constant light. In fact, as described by Hennessey et al. (1993) for this species, non-structural carbohydrates accumulated steadily under continuous illumination, but apparently without inducing feedback inhibition of photosynthesis.

Alternatively, rhythms in photosynthesis could be explained by the synthesis/degradation of chlorophyll and its binding proteins, a process that has been observed in young leaves of wheat where LHCII content peaks at noon coinciding with the minimum Chla/b ratio (Busheva et al. 1991). As occurred with photochemical responses, Chla/b ratio oscillated in bean, and less markedly in cotton. Furthermore, the oscillations in bean occurred both under continuous illumination and under continuous darkness (Fig $4 \underline{\mathrm{b} 3 \mathrm{~b}}$ ). Chla/b is the resultant of two factors: on one hand, Chla is present in antennae and reaction centers of both PSI and PSII, while Chl $b$ is exclusively bound to antenna proteins of both photosystems (Hogewoning et al. 2012). On the other hand, PSII is comparatively enriched in Chlb, with most of it bound to major light-harvesting complexes (LHCs). These complexes form trimers that are bound in variable ways to dimeric PSII core complexes ( $\mathrm{C} 2)$ forming the $\mathrm{C} 2 \mathrm{~S} 2$, the $\mathrm{C} 2 \mathrm{~S} 2 \mathrm{M}$, the $\mathrm{C} 2 \mathrm{~S} 2 \mathrm{M} 2$ or the C2S2M2L2 super-complexes, with respectively 2, 3, 4 or 6 trimers (Derks et al. 2015). As a consequence of the different amount of LHC trimers bound to PSII, Chl $a / b$ reflects the PSII/PSI stoichiometry, but also the relative antenna size (Evans 1988). In shaded leaves of higher plants, which optimize light harvesting at the expense of energy conversion and photoprotection, high LHC relative to PSII and low PSII/PSI ratio are mirrored in Chla/b ratios in the range of 2 to 2.8. Conversely, in high light acclimated 
leaves, Chla/b values are higher (2.8 to 4) (Hogewoning et al. 2012; Esteban et al. 2015). Thus, the reported oscillations of Chla/b, whose adjustments ranged between 3.3 and 3.6 for bean and between 3.4 and 3.7 for cotton, are likely due to the synthesis and/or degradation of trimeric LHCIIs, that bind most of Chlb. Using the model proposed by Esteban et al. (2015) this range of oscillation, assuming a PSII/PSI ratio of 2 (Antal et al. 2013), would represent a net daily variation of around 0.8 LHCII trimers per PSII dimer. Considering that Chl-binding proteins represent about $20 \%$ of leaf $\mathrm{N}$ (Hötensteiner 2006), this turnover rate represents a tremendous metabolic effort in terms of energy and $\mathrm{N}$ use.

It is considered that the abundance and binding properties of LHCII trimers regulate the acclimation capacity to long-term changes in light environment (Kouril et al. 2013; Ware et al. 2015), while the stoichiometry of minor antenna complexes and reaction centers is usually maintained stable (Ballottari et al. 2007). Interestingly, Chla/b peaked during subjective nights, implying that the capacity for light harvesting (larger antenna) is minimal at night, being maximal around subjective noon. This interpretation is consistent with the described midday peaks in the circadian patterns of expression of genes involved in Chl biosynthesis (Fukushima et al. 2009; Harmer et al. 2000; Khan et al. 2010), carotenoid biosynthesis (Facella et al. 2008; Ragni and Ribera d'Alcalà 2007; Pan et al. 2009), Chl-binding proteins (in particular LHCII, whose expression is maximum at noon) (Hotta et al. 2007; Schmid et al. 2008) and carbon assimilation (Harmer et al. 2000). This pattern of change seems counterintuitive if we assume that the plant strategy is to avoid photo-damage, but is fully consistent with a model in which non-stressed plants maximize photosynthesis. In fact, considering that the risk of photo-oxidative damage is higher around sunrise due to the combination of high light and sub-optimal temperatures, the enhancement of photo-protective response at night could be considered as a pre-emptive response. This is also supported by the fact that before sunrise there is an enhancement in the expression of photo-protective genes such as those of flavonoids (Harmer et al. 2000), tocopherols and carotenoids (Covington et al. 2008) and cold protection (Yakir et al. 2007). However, considering that light excess is concomitant with reactive oxygen species (ROS) generation, it is surprising that ROS-responsive genes are not clock regulated (Sanchez et al. 2011). All these processes could, at least partially, contribute to explain the marked oscillations of carbon assimilation (Fig. 1) that cannot be solely ascribed to changes in stomatal 
conductance, being in agreement with the proposal that links circadian oscillations in chlorophyll content with carbon assimilation (Müller et al. 2014).

As indicated before, the structure of photosynthetic apparatus determines the Chla/b ratio, and this parameter has shown a robust oscillatory behaviour. This fact, together with the feasibility of Chla/b determination, makes this parameter an excellent reporter of the photosynthetic output of circadian oscillations. Furthermore, as Chla/b can be easily estimated with reflectance indexes (Siebke \& Ball 2009), it can be used as a noninvasive reporter of rhythmicity in phenotyping or remote sensing platforms using hyperspectral images (Pan et al. 2015), complementing other circadian reporters currently available such as delayed chlorophyll fluorescence and transgenic luciferase (Tindall et al. 2016).

Overall, the present results suggest that there is no single, universal response to the dilemma between maximizing light harvesting and avoiding photo-damage. We have studied two species and have found two types of clock-responses in photosynthetic pigments. Thus, in bean there was a higher circadian regulation of photochemical processes and pigment composition, while in cotton carbohydrate metabolism was apparently clock regulated. As a consequence, extrapolation of the responses from Arabidopsis and other model plants to other species is not always appropriate (Müller et al. 2014), making necessary the use of additional reporters of circadian rhythms.

\section{ACKNOWLEDGEMENTS}

The authors acknowledge the support of the following research grants: UPV/EHU-GV IT-624-13 and IT-1018-16 from the Basque Government, CTM2014-53902-C2-2-P from the Spanish Ministry of Economy and Competitiveness (MINECO) and the ERDF (FEDER). This study benefited from the CNRS human and technical resources allocated to the ECOTRONS Research Infrastructures as well as from the state allocation 'Investissement d'Avenir' ANR-11-INBS-0001, ExpeER FP7 Transnational Access program, Ramón y Cajal fellowships (RYC-2012-10970 to VRD and RYC-2008-02050 to JPF), the Erasmus Mundus Master Course Mediterranean Forestry and Natural Resources Management (MEDfOR) and internal grants from UWS-HIE to VRD and ZALF to AG. EHU postdoctoral fellowship and JdC-Incorporation fellowship (IJCI2014-22489) to BFM are also acknowledged. We remain indebted to E. Gerardeau, D. 
476 Dessauw, J. Jean, P. Prudent (Aïda CIRAD), J.-J. Drevon, C. Pernot (Eco\&Sol INRA),

477 B. Buatois, A. Rocheteau (CEFE CNRS), S. Devidal, C. Piel, O. Ravel and the full

478 Ecotron team, J. del Castillo, P. Martín, A. Mokhtar, A. Pra, S. Salekin (UdL), S.

479 García-Muñoz (IMIDRA), Z. Kayler and K. Pirhofer-Walzl (ZALF) A. Pra, A.

480 Mokhtar, C.V.M. Barton and the full Ecotron team, in particular C. Escape, for

481 outstanding technical assistance during experiment set-up, plant cultivation or 482 subsequent measurements. 


\section{REFERENCES}

Antal T.K., Kovalenko I.B., Rubin A.B. \& Yyystjärvi E. (2013) Photosynthesis-related quantitites for education and modeling. Photosynthesis Research 117, 1-30.

Audran C., Borel C., Frey A., Sotta B., Meyer C., Simonneau T. \& Marion-Poll A. (1998) Expression studies of the zeaxanthin epoxidase gene in Nicotiana plumbaginifolia. Plant Physiology 118, 1021-1028.

Ballottari M., Dall'Osto L., Morosinoto T. \& Bassi R. (2007) Contrasting behavior of higher plant photosystem I and II antenna systems during acclimation. The Journal of Biological Chemistry 282, 8947-8958.

Bell-Pedersen D., Cassone V.M., Earnest D.J., Golden S.S., Hardin P.E., Thomas T.L. \& Zoran M.J. (2005) Circadian rhythms from multiple oscillators: lessons from diverse organisms. Nature Reviews Genetics 6, 544-556.

Busheva M., Garab G., Liker E., Toth Z., Szell M. \& Nagy F. (1991) Diurnal fluctuations in the content and functional properties of the light harvesting chlorophyll a/b complex in thylakoid membranes. Plant Physiology 95, 997-1003.

Cazzaniga S., Dall'Osto L., Kong S.G., Wada M. \& Bassi R. (2013) Interaction between avoidance of photon absorption, excess energy dissipation and zeaxanthin synthesis against photooxidative stress in Arabidopsis. Plant Journal 76, 568-579.

Covington M.F., Maloof J.N., Straume M., Kay S.A. \& Harmer S.L. (2008) Global transcriptome analysis reveals circadian regulation of key pathways in plant growth and development. Genome Biology 9, R130.

Derks A., Schaven K. \& Bruce D. (2015) Diverse mechanisms for photoprotection in photosynthesis. Dynamic regulation of photosystem II excitation in response to rapid environmental change. Biochimica et Biophysica Acta 1847, 468-485.

Dodd A.N., Parkinson K. \& Webb A.A.R. (2004) Independent circadian regulation of assimilation and stomatal conductance in the $z t l-1$ mutant of Arabidopsis. New Phytologist 162, 63-70.

Dodd A.N., Salathia N., Hall A., Kévei E., Tóth R., Nagy F., ..., Webb A.A.R. (2005) Plant circadian clocks increase photosynthesis, growth, survival, and competitive advantage. Science 309, 630-633. 
Dodd A.N., Kusakina J., Hall A., Gould P.D. \& Hanaoka M. (2014) The circadian regulation of photosynthesis. Photosynthesis Research 119, 181-190.

Doughty C., Goulden M.L., Miller S. \& da Rocha H. (2006) Circadian rhythms constrain leaf and canopy gas exchange in an Amazonian forest. Geophysical Research Letters 33, L15404.

Endo M. (2016) Tissue-specific circadian clocks in plants. Current Opinion in Plant Biology 29, 44-49.

Esteban R., Barrutia O., Artetxe U., Fernández-Marín B., Hernández A. \& GarcíaPlazaola J.I. (2015). Internal and external factors affecting photosynthetic pigment composition in plants: a meta-analytic approach. New Phytologist 206, 268-280.

Evans J.R. (1988) Acclimation by the thylakoid membranes to growth irradiance and the partitioning of nitrogen between soluble and thylakoid proteins. Australian Journal of Plant Physiology 15, 93-106.

Facella P., Lopez L., Carbone F., Galbraith D.W., Giuliano G. \& Perrotta G. (2008) Diurnal and circadian rhythms in the tomato transcriptome and their modulation by cryptochrome photoreceptors. PLoS ONE 3, e2798.

Farquhar G.D. \& Sharkey T.D. (1982) Stomatal conductance and photosynthesis. Annual Review of Plant Physiology and Plant Molecular Biology 33, 317-345.

Flexas J., Barbour M.M., Brendel O., Cabrera H.M., Carriqui M., Diaz-Espejo A., ..., Warren C.R. (2012) Mesophyll diffusion conductance to $\mathrm{CO}_{2}$ : an unappreciated central player in photosynthesis. Plant Science 193-194, 70-84.

Fukushima A., Kusano M., Nakamichi N., Kobayasho M., Hayashi N., Sakakibara H., Mizuno T. \& Saito K. (2009). Impact of clock-associated Arabidopsis pseudoresponse regulators in metabolic coordination. Proceedings of the National Academy of Sciences USA 106, 7251-7256.

García-Plazaola J.I. \& Becerril J.M. (1999) A rapid HPLC method to measure lipophilic antioxidants in stressed plants: simultaneous determination of carotenoids and tocopherols. Phytochemical Analysis 10, 307-313.

García-Plazaola J.I. \& Becerril J.M. (2001) Seasonal changes in photosynthetic pigments and antioxidants in beech (Fagus sylvatica) in a Mediterranean climate: 
implications for tree decline diagnosis. Australian Journal of Plant Physiology 28, 225-232.

García-Plazaola J.I., Esteban R., Fernández-Marín B., Kranner I. \& Porcar-Castell A. (2012) Thermal energy dissipation and xanthophyll cycles beyond the Arabidopsis model. Photosynthesis Research 113, 89-103.

Genty B., Briantais J.M. \& Baker N.R. (1989) The relationship between the quantum yield of photosynthetic electron transport and quenching of chlorophyll fluorescence. Biochimica et Biophysica Acta 990, 87-92.

Gibon Y., Bläsing O.E., Palacios-Rojas N., Pankovic D., Hendriks J.H.M., Fisahn J., ..., Stitt M. (2004) Adjustment of diurnal starch turnover to short days: depletion of sugar during the night leads to a temporary inhibition of carbohydrate utilization, accumulation of sugars and post-translational activation of ADP-glucose pyrophosphorylase in the following light period. Plant Journal 39, 847-862.

Gould P.D., Diaz P., Hogben C., Kusakina J., Salem R., Hartwell J. \& Hall A. (2009) Delayed fluorescence as a universal tool for the measurement of circadian rhythms in higher plants. Plant Journal 58: 893-901.

Graf A., Schlereth A., Stitt M., \& Smith A.M. (2010) Circadian control of carbohydrate availability for growth in Arabidopsis plants at night. Proceedings of the National Academy of Sciences USA 107, 9458-9463.

Hanano S., Stracke R., Jakoby M., Merkle T., Domagalska M.A., Weisshaar B. \& Davis S.J. (2008) A systematic survey in Arabidopsis thaliana of transcription factors that modulate circadian parameters. BMC Genomics 9, 182.

Harmer S.L., Hogenesch J.B., Straume M., Chang H.S., Han B., Zhu T., .., Kay S.A. (2000) Orchestated transcription of key pathways in Arabidopsis by the circadian clock. Science 290, 2110-2113.

Harmer S.L. (2009) The circadian system in higher plants. Annual Review of Plant Biology 60, 357-377.

Haydon M.J., Mielczarek O., Robertson F.C., Hubbard K., \& Webb A.A.R. (2013) Photosynthetic entrainment of the Arabidopsis thaliana circadian clock. Nature 502, 689-692. 
Hennessey T., Freeden A. \& Field C. (1993) Environmental effects on circadian rhythms in photosynthesis and stomatal opening. Planta 189, 369-376.

Hoch G., Popp M. \& Körner C. (2002) Altitudinal increase of mobile carbon pools in Pinus cembrasuggests sink limitation of growth at the Swiss treeline. Oikos 98, 361374.

Hogewoning S.W., Wientjes E., Douwstra P., Trouwborst G., van Leperen W., Croce R. \& Harbison J. (2012) Photosynthetic quantum yield dynamics: from photosystems to leaves. The Plant Cell 24, 1921-1935.

Hörtensteiner S. (2006) Chlorophyll degradation during senescence. Annual Review of Plant Biology 57, 55-77.

Hotta C.T., Gardner M.J., Hubbard K.E., Baek S.J., Dalchau N., Suhita D., Dodd A.N. \& Webb A.A.R. (2007) Modulation of environmental responses of plants by circadian clocks. Plant Cell and Environment 30, 333-349.

Khan S., Rowe S.C. \& Harmon F.G. (2010) Coordination of the maize transcriptome by a conserved circadian clock. BMC Plant Biology 10, 126.

Kouril R., Wientjes E., Bultema J.B., Croce R. \& Boekema E.J. (2013) High-light vs. low-light: effect of light acclimation on photosystem II composition and organization in Arabidopsis thaliana. Biochimica et Biophysica Acta 1827, 411-419.

Eitthauer S., Battle M.W., Lawson T. \& Jones M.A. (2015) Phototropins maintain robust circadian oscillation of PSII operating efficiency under blue light. The Plant Journal 83, 1034-1045.

McClung C.R. (2006) Plant circadian rhythms. The Plant Cell 18, 792-803.

McClung C.R. (2013) Beyond Arabidopsis: the circadian clock in non-model plant species. Seminars in Cell \& Developmental Biology 24, 430-436.

Milcu A., Roscher C., Gessler A., Bachmann D., Gockele A., Guderle M., ..., Roy J. (2014) Functional diversity of leaf nitrogen concentrations drives grassland carbon fluxes. Ecology Letters 17: 435-444.

Müller L.M., von Korff M. \& Davis S.J. (2014) Connections between circadian clocks and carbon metabolism reveal species-specific effects on growth control. Journal of Experimental Botany 65: 2915-2923. 
Munger P., Bleiholder H., Hack H., Heß M., Strauss R., van den Boom T. \& Weber E. (1998) Phenological growth stages of the peanut plant (Arachis hypogaea L.) Codification and description according to the BBCH Scale. Journal of Agronomy and Crop Science 180, 101-107.

Noordally Z.B., Ishii K., Atkins K.A., Wetherill S.J., Kusakina J., Walton A.J., ..., Dodd A.N. (2013) Circadian control of chloroplast transcription by a nuclearencoded timing signal. Science 339, 1316-1319.

Pallas J.E., Samish Y.B. \& Willmer C.M. (1974) Endogenous rhythmic activity of photosynthesis, transpiration, dark respiration, and carbon dioxide compensation point of peanut leaves. Plant Physiology 53, 907-911.

Pan Y., Michael T.P., Hudson M.E., Kay S.A., Chory J. \& Schuler M.A. (2009) Cytochrome P450 monooxygenase as reporters for circadian-regulated pathways. Plant Physiology 150, 858-878.

Pan W.J., Wang X., Deng Y.R., Li J.H., Chen W., Chiang J.Y., Yang J.B. \& Zheng L. (2015) Nondestructive and intuitive determination of circadian chlorophyll rhythms in soybean leaves using multispectral imaging. Sientific Reports 5, 11108.

Ragni M. \& Ribera d'Alcalà M. (2007) Circadian variability in the photobiology of Phaeodactylum tricornutum: pigment content. Journal of Plancton Research 29, 141-156.

Resco de Dios V., Goulden M.L., Ogle K., Richardson A.D., Hollinger D.Y., Davidson E.A., ..., Moreno J.M. (2012) Endogenous circadian regulation of carbon dioxide exchange in terrestrial ecosystems. Global Change Biology 18, 1956-1970.

Resco de Dios V., Roy J., Ferrio J.P., Alday J.G., Landais D., Milcu A., \& Gessler A. (2015) Processes driving nocturnal transpiration and implications for estimating land evapotranspiration. Scientific Reports 5, 10975.

Resco de Dios V., Loik M.E., Smith R.A., Aspinwall M.J. \& Tissue D.T. (2016a) Genetic variation in circadian regulation of nocturnal stomatal conductance enhances plant fitness. Plant Cell and Environment 39, 3-11.

Resco de Dios V., Gessler A., Ferrio J.P., Alday J.G., Bahn M., del Castillo J., ..., Roy J. (2016b) Circadian rhythms have significant effects on leaf-to-canopy gas exchange under field conditions. Giga Science doi: 10.1101/054593 $\underline{\text {, } 43}$. 
Salmela M.J., Greenham K., Lou P., McClung C.R., Ewers B.E. \& Weinig C. (2016) Variation in circadian rhythms is maintained among and within populations in Boechera stricta. Plant Cell and Environment 39, 1293-1303.

Sanchez A, Shin J. \& Davis S.J. (2011) Abiotic stress and the plant cireadian clock. Plant Signalling and Behaviour 6, 223231.

Schmid V.H.R. (2008) Light-harvesting complexes of vascular plants. Cellular and Molecular Life Sciences 65, 3619-3639.

Siebke K. \& Ball M.C. (2009) Non-destructive measurement of chlorophyll $b: a$ ratios and identification of photosynthetic pathways in grasses by reflectance spectroscopy. Functional Plant Biology 36, 857-866.

Sorek M., Yacobi Y.Z., Roopin M., Berman-Frank I. \& Levy O. (2013) Photosynthetic circadian rhythmicity patterns of Symbiodium, the coral endosymbiotic algae. Proceedings of the Royal Society B 280, 20122942.

Tindall A.J., Waller J., Greenwood M., Gould P.D., Hartwell J. \& Hall A. (2016) A comparison of high-throughput techniques for assaying circadian rhythms in plants. Plant Methods 11, p. 32.

Ware M.A., Belgio E. \& Ruban A.V. (2015) Photoprotective capacity of nonphotochemical quenching in plants acclimated to different light intensities. Photosynthesis Research 126, 261-274.

Wood S.N. (2006) Generalized Additive Models: An Introduction. R. (Chapman \& Hall/CRC: Boca Raton, Florida).

Wyka TP, Duarte HM \& Lüttge UE (2005) Redundancy of stomatal control for the circadian photosynthetic rhythm in Kalanchoë daigremontiana Hamet et Perrier. Plant Biology 7: 176-181.

Yakir E., Hilman D., Harir Y. \& Green R.M. (2007) Regulation of output from the plant circadian clock. FEBS Journal 274, 335-345.

Yarkhunova Y., Edwards C.E., Ewers B.E., Baker R.L., Aston T.L., McClung C.R., Lou P. \& Weinig C. (2016) Selection during crop diversification involves correlated evolution of the circadian clock and ecophysiological traits in Brassica rapa. New Phytologist 210, 133-144. 
665 Yerushalmi S. \& Green R.M. (2009) Evidence for the adaptive significance of circadian 666 rhythms. Ecology Letters 12, 970-981.

667 Zhao W., Wang S., Li X., Huang H., Sui X. \& Zhang Z. (2012) Molecular cloning and 668 characterization of the light-regulation and circadian-rhythm of the VDE gene 669 promoter from Zingiber officinale. Plant Cell Reports 31, 1381-1392.

670

671

672

673 
FIGURES

675 Figure 1. Net assimilation ( $\left.A_{\text {net }}\right)\left(\right.$ a), stomatal conductance $\left(g_{\mathrm{s}}\right)(\mathrm{b}), A_{\text {net }} / C_{\mathrm{i}}$ ratio (c) and photosynthetic capacity $\left(A_{\max }\right)(\mathrm{d})$ in bean (P. vulgaris) and cotton (G. hirsutum) leaves during the last cycle of the entrainment phase and under continuous illumination and constant environmental conditions. The grey section corresponds to the last dark period of an entrainment phase of five days. Black and white segments on the $\mathrm{X}$-axis represent subjective nights (i.e. when the plants would have naturally experienced night-time conditions) and days (i.e. when the plants would have naturally experienced day-time

682

683

684

685

686

687

688

689

690

691

692

693

694

695

696

697

698

699

700

701

702

703

704

705 conditions), respectively. Time zero represents the first subjective noon after transfer to constant conditions. Temporal patterns were examined with Generalized Additive Model (GAM) fitted with automated smoothness selection (Wood 2006). Shaded areas indicate SE of GAM fitting.

Figure 2. Actual photochemical efficiency of PSII ( $\left.\Phi_{\text {PSII }}\right)($ a), maximal fluorescence of illuminated leaves at steady-state (Fm') under continuous illumination and constant environmental conditions (b), non-photochemical quenching (NPQ) (bç) and maximal fluorescence of dark-adapted leaves (Fm) during the last cycle of the entrainment phase and under continuous darkness and constant environmental conditions (d) in bean (P. vulgaris) and cotton ( $G$. hirsutum) leaves during the last cycle of the entrainment phase and under continuous illumination and constant environmental conditions. The grey section corresponds to the last dark period of an entrainment phase of five days. Black and white segments on the $\mathrm{X}$-axis represent subjective nights and days, respectively. $\underline{\text { Statistical analysis and data presentation as in Fig. } 1 .}$

Figure 3. Maximal fluorescence of illuminated leaves at steady-state (Fm') under continuous illumination and constant environmental conditions (a) and maximal fluorescence of dark adapted leaves (Fm) during the last cycle of the entrainment phase and under continuous darkness and constant environmental conditions (b), in bean ( $P$. whlgaris) and cotton (G. hirsutum) leaves. The grey section corresponds to the last dark period of an entrainment phase of five days. Black and white segments on the $X$ axis represent subjective nights and days, respectively. Statistical analysis and data presentation as in Fig. 1. 
Figure 4․ Ratio of chlorophyll $a$ to chlorophyll $b(\mathrm{Chl} a / b)$ in bean (P. vulgaris) and cotton ( $G$. hirsutum) leaves under continuous illumination and constant environmental conditions (a) and in bean leaves during the last cycle of the entrainment phase and under continuous darkness and constant environmental conditions (b). The grey section corresponds to the last dark period of an entrainment phase of five days. Black and white segments on the $\mathrm{X}$-axis represent subjective nights and days, respectively. Statistical analysis and data presentation as in Fig. 1.

Figure 54. Ratio of total pool of xanthophyll cycle pigments (violaxanthin + antheraxanthin + zeaxanthin) to chlorophyll (VAZ/Chl) (a), deepoxidation state of the xanthophyll cycle (AZ/VAZ) (b) and total carotenoid to chlorophyll (c) in bean ( $P$. vulgaris) and cotton ( $G$. hirsutum) leaves during the last cycle of the entrainment phase and under continuous illumination and constant environmental conditions. The grey section corresponds to the last dark period of an entrainment phase of five days. Black and white segments on the $\mathrm{X}$-axis represent subjective nights and days, respectively. $\underline{\text { Statistical analysis and data presentation as in Fig. } 1 .}$

Figure 65. Total pool of non-structural carbohydrates (NSC) (a) and starch (b) in bean (P. vulgaris) and cotton (G. hirsutum) leaves during the last cycle of the entrainment phase and under continuous illumination and constant environmental conditions. The grey section corresponds to the last dark period of an entrainment phase of five days. Black and white segments on the $\mathrm{X}$-axis represent subjective nights and days, conductance $\left(g_{\mathrm{s}}\right)$ (a), internal $\mathrm{CO}_{2}$ concentration $\left(C_{\mathrm{i}}\right)$ (b), actual photochemical efficiency of PSII ( $\left.\Phi_{\mathrm{PSII}}\right)(\mathrm{c})$ and ratio of chlorophyll $a$ to chlorophyll $b(\mathrm{Chl} a / b)$ (d) in bean ( $P$. vulgaris) and cotton (G. hirsutum) leaves during the last cycle of the entrainment phase and under continuous illumination and constant environmental 
737 conditions. Linear regressions are shown when significant at $\mathrm{P}<0.05$. Dotted lines

738 represent non-significant regressions.

739

740

741 


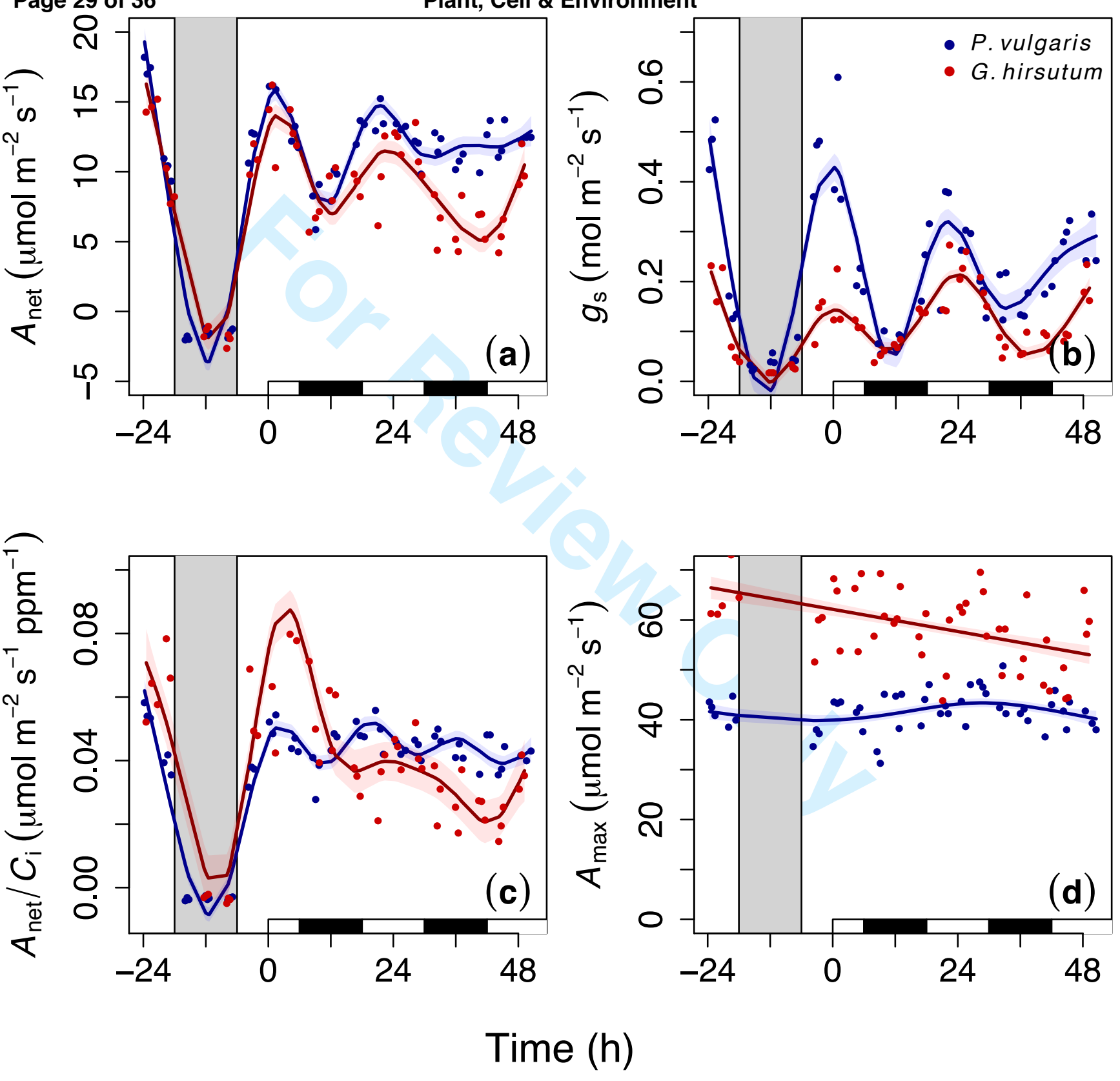



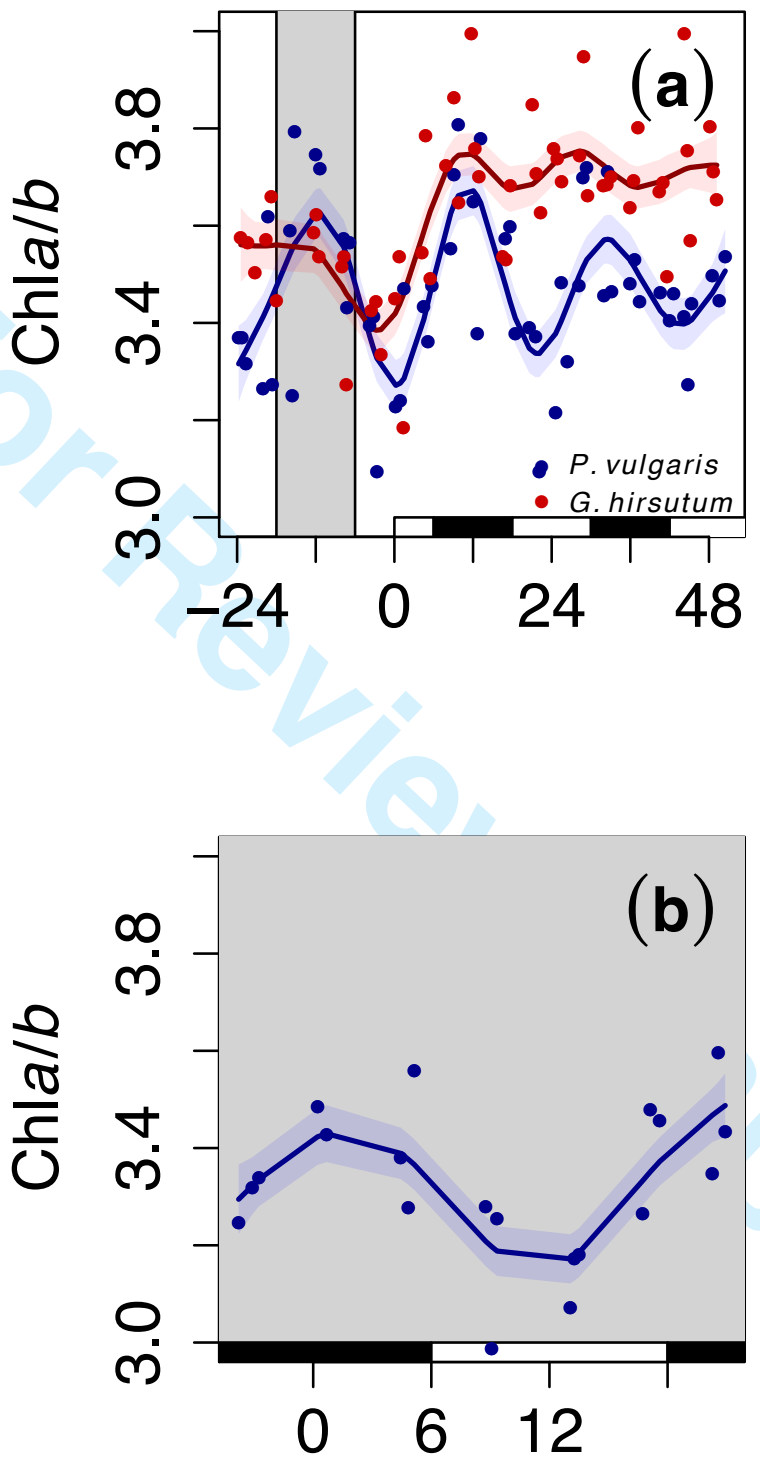

Time (h) 

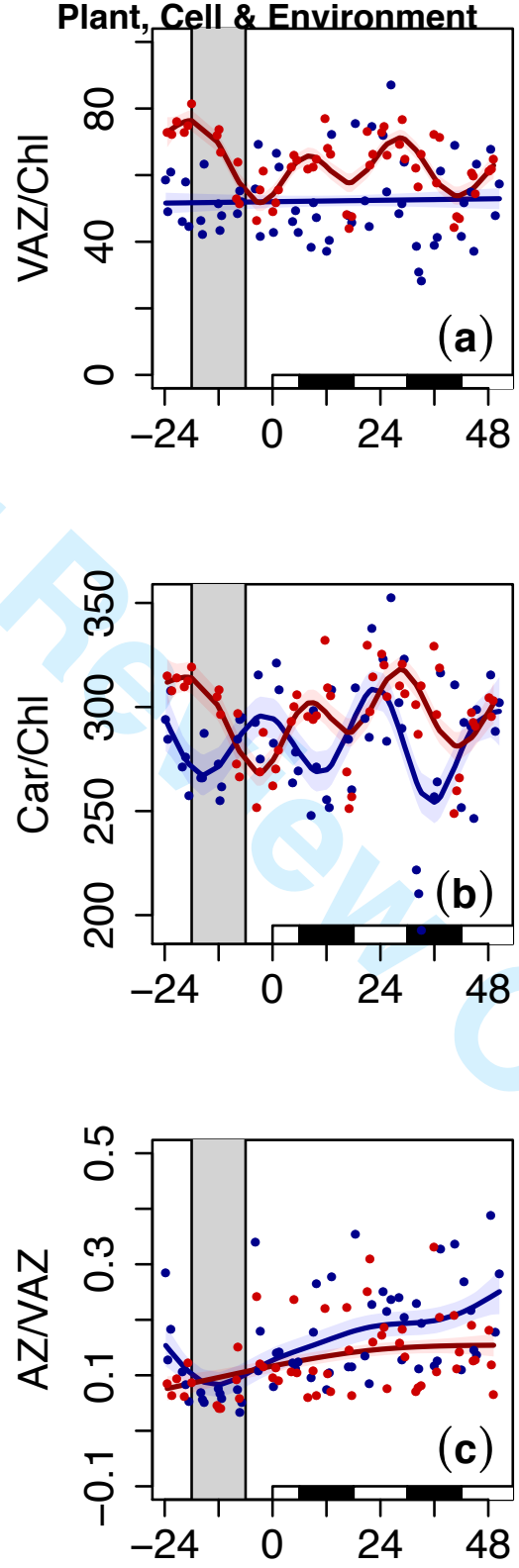
Plant, Cell \& Environment

Page 34 of 36
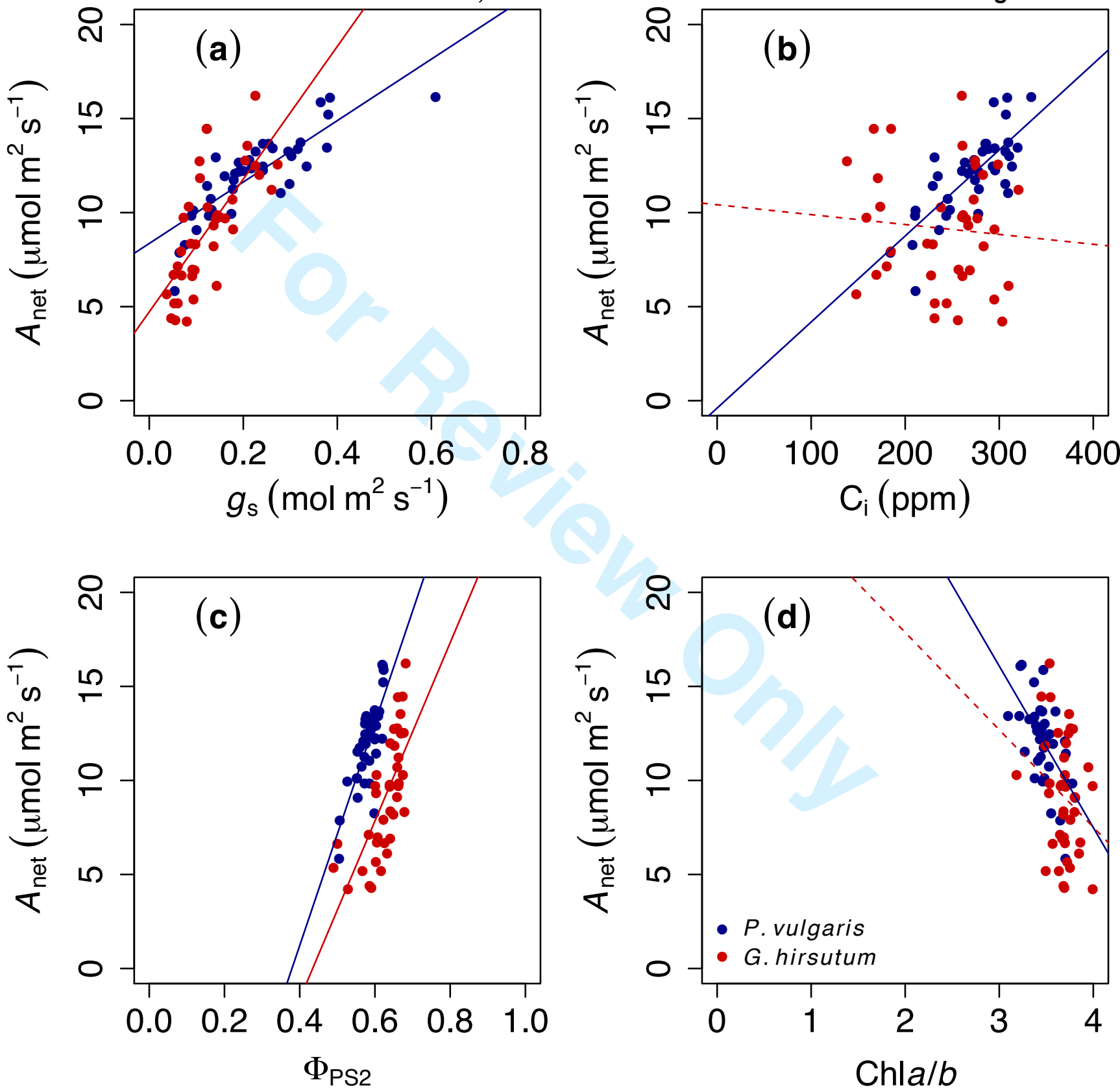


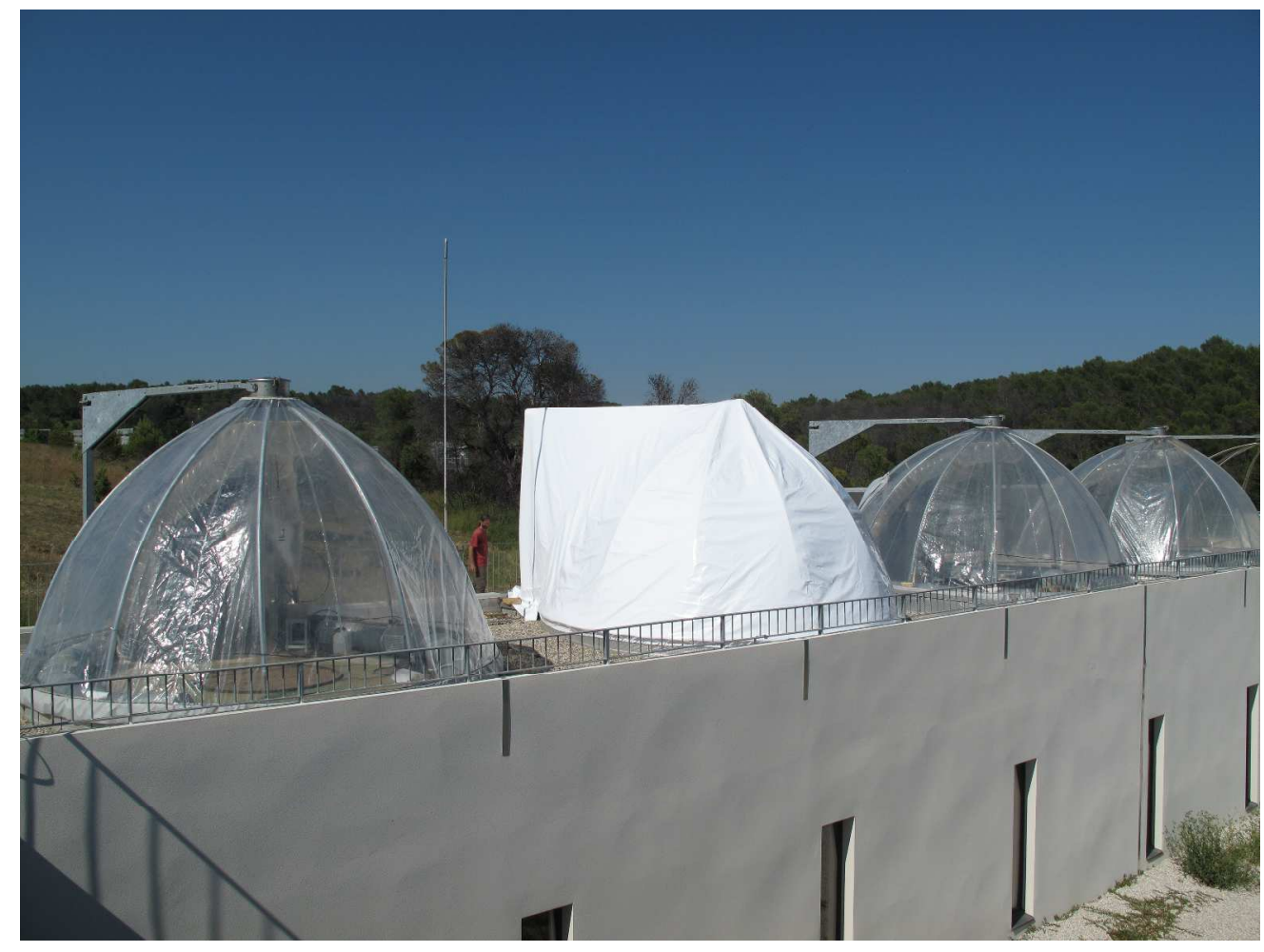

Macrocosms platform of the Montpellier European Ecotron (Courtesy of J. Roy) $623 \times 467 \mathrm{~mm}(180 \times 180 \mathrm{DPI})$ 


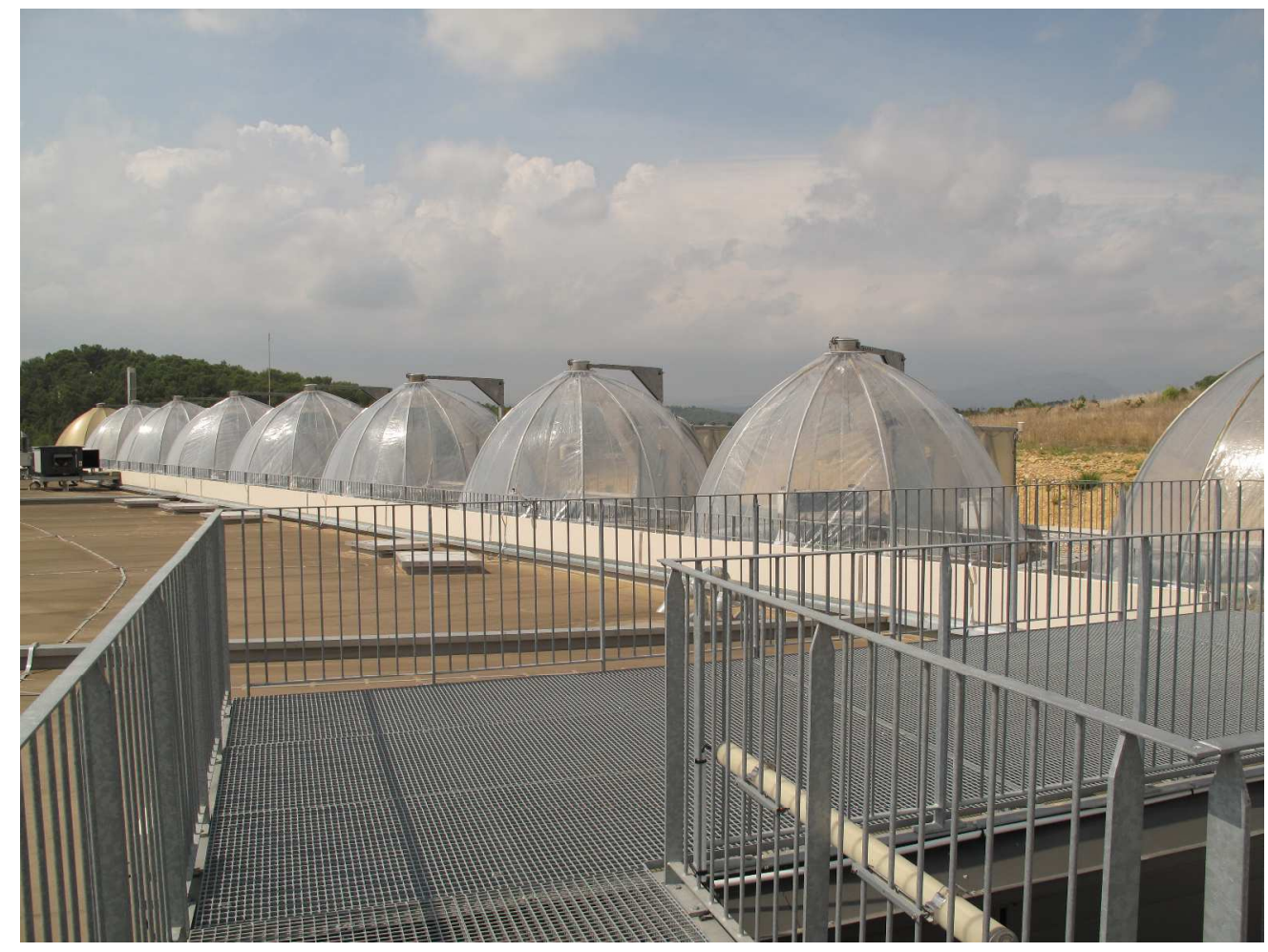

Macrocosms platform of the Montpellier European Ecotron (Courtesy of J. Roy). $623 \times 467 \mathrm{~mm}(180 \times 180 \mathrm{DPI})$ 


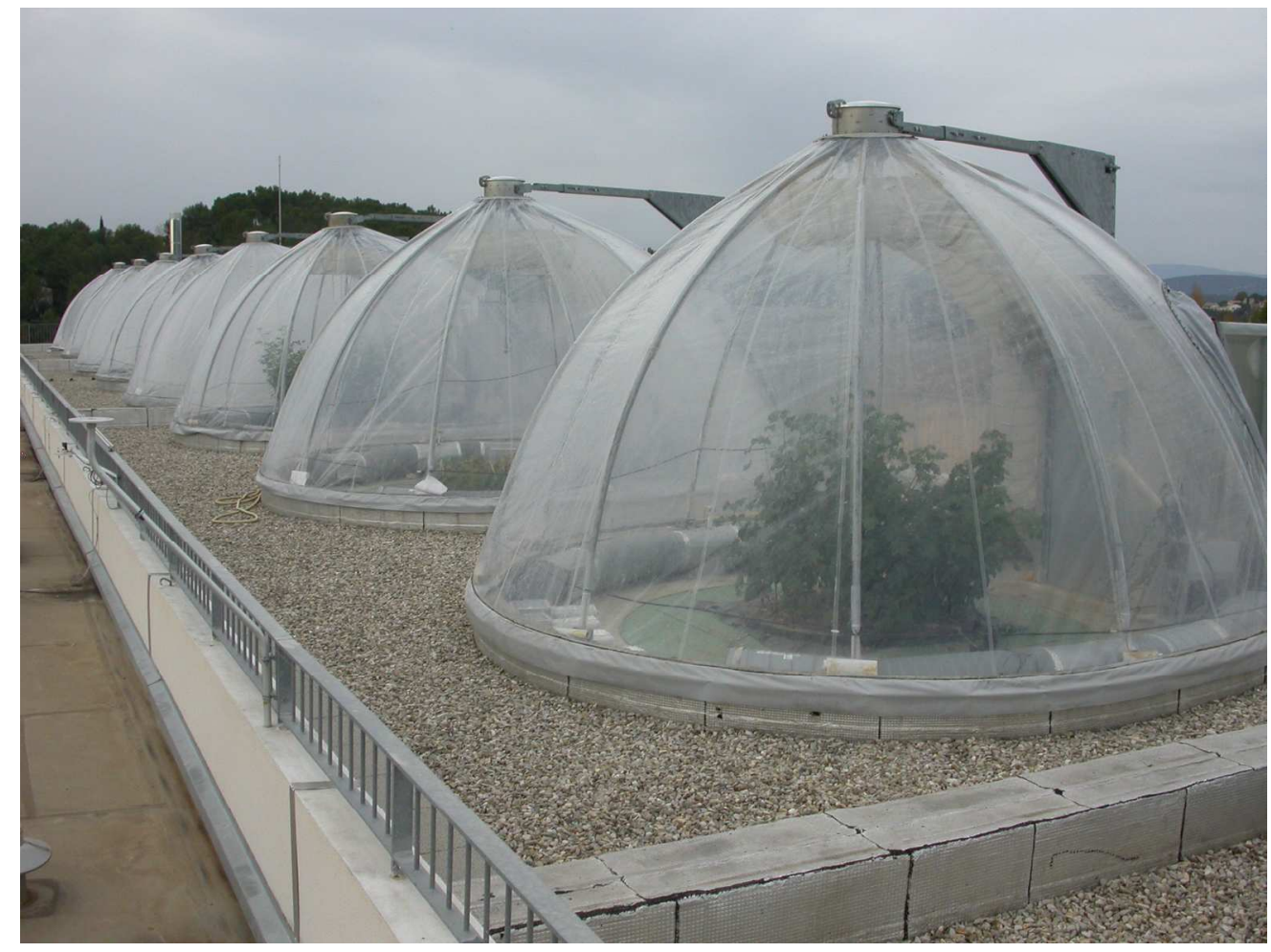

Macrocosms platform of the Montpellier European Ecotron (Courtesy of J. I. García-Plazaola) $192 \times 144 \mathrm{~mm}(300 \times 300$ DPI $)$ 